\title{
Use of Quality Measures for Rural Indian Fingerprint Image Database Enhancement and Improve the Recognition Rate
}

\author{
Babasaheb V. Bhalerao \\ Department of CS and IT \\ Dr. B. A.M. University, \\ Aurangabad (MS), India
}

\author{
Dr. Ramesh R. Manza \\ Department of CS and IT \\ Dr. B. A.M. University, \\ Aurangabad (MS), India
}

\author{
Yogesh M. Rajput \\ Department of CS and IT \\ Dr. B. A.M. University, \\ Aurangabad (MS), India
}

\begin{abstract}
Identification and authentication is done using various biometric sign like fingerprints. The recognition rate of correct person is depending on quality of fingerprints images. Fingerprints quality also varying from rural and urban population. Rural population having more physical work than urban population. Therefore the ridges, valleys, bifurcation, joints, minutia etc. features are not good quality hence it reduces recognition rate accuracy. To improve recognition rate of such images there is strong need to first improve the quality of features. In this paper used the rural fingerprints database which is collected from IIIT Delhi research lab which consists of 1632 fingerprints images. Out of which preprocess 100 sample images using histogram equalization and tried to improve the quality of images. The resultant images quality is verified by using different quality measures like PSNR, MSE, MAXERR, L2RAT, it is found that quality has been improved. Hence it is proved that the recognition rate is increases.
\end{abstract}

\section{Keywords}

Rural fingerprints, Histogram equalization, PSNR, MSE, L2rat.

\section{INTRODUCTION}

Perform preprocessing operation to enhance rural fingerprint database images and determine statistical measure PSNR, MSE, MAXERR, L2rat. Found good result with enhancement algorithms. In the fingerprints recognition system the main objective of the fingerprints enhancement algorithm is to reduce low quality noisy images of rural fingerprints databases. There are several factors that affect the quality of fingerprints image videlicet presence of noisy fingerprints images variations of pressure between the fingerprints and acquisition sensor, worn artifacts and environmental conditions during acquisition process. An input fingerprint image is thereby transfer by the enhancement algorithm to reduce the noisy fingerprint images. The rural fingerprints database collected from IIIT Delhi research lab. Perform various algorithms, techniques and tools for automatic recognition of humans. The fingerprint database enables researches in developing, testing and publishing human recognition algorithms. Image Analysis and Biometrics (IAB) Lab at Indraprastha Institute of Information Technology have done very good work on rural fingerprint database.
Figure1: Rural fingerprint images from IIIT Delhi
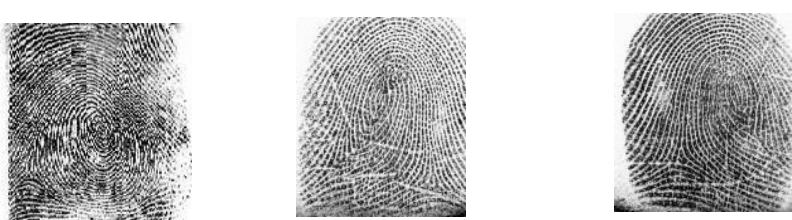

The performance of automatic fingerprint identification system relies heavily on the quality of the fingerprint images. Poor quality images result in missing or spurious features, thus degrading the performance of the identification system. Therefore, it is important for a fingerprint identification system to estimate the quality of the captured fingerprint images.

\section{Methodology}

PSNR: PSNR is the peak signal to noise ratio in decibels. The PSNR is only meaningful for data encoded in terms of bits per sample, or bits per pixel. For example, an image with 8 bits per pixel contains integers from 0 to 255 .

MSE: The mean square error (MSE) is the squared norm of the difference between the data and the approximation divided by the number of elements.

MAXERR: MAXERR is the maximum absolute squared deviation of the data from the approximation.

L2RAT: L2RAT is the ratio of the squared norm of the signal or image approximation to the input signal or image.

Peak signal-to-noise ratio (PSNR) is an expression for the ratio between the maximum possible value (power) of a signal and the power of distorting noise that affects the quality of its representation. Because many signals have a very wide dynamic range the PSNR is usually expressed in terms of the logarithmic decibel scale. Image enhancement or improving the visual quality of a digital image can be subjective. Saying that one method provides a better quality image could vary from person to person. For this reason, it is necessary to establish quantitative/empirical measures to compare the effects of image enhancement algorithms on image quality using the same set of tests images, different image enhancement algorithms can be compared systematically to identify whether a particular algorithm produces better results. The metric under investigation is the peak-signal-to-noise ratio. If we can show that an algorithm or set of algorithms can enhance a degraded known image to more closely resemble the original, then we can more accurately conclude that it is a better algorithm. 


$$
P S N R=20 \log _{10}\left(\frac{M A X_{f}}{\sqrt{M S E}}\right)
$$

The mathematical representation of the PSNR is as follows:

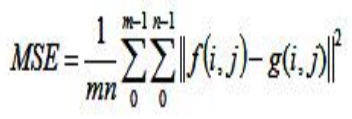

$$
\operatorname{MSE}=\left(1 /\left(m^{*} n\right)\right) * \operatorname{sum}\left(\operatorname{sum}\left((f-g) \cdot \wedge^{\wedge}\right)\right)
$$

$$
\text { PSNR }=20 * \log (\max (\max (f))) /((M S E) \wedge 0.5)
$$

Where the MSE (Mean Squared Error) is:

This can also be represented in a text based format as:

\section{Where Represent}

frepresents the matrix data of our original image. grepresents the matrix data of our degraded image in question. $\mathrm{m}$ represents the numbers of rows of pixels of the images and irepresents the index of that row. nrepresents the number of columns of pixels of the image and $\mathrm{j}$ represents the index of that column.

MAXRR is the maximum signal value that exists in our original "known to be good" image. The mean square error or MSE of an estimator is one of many ways to quantify the difference between an estimator and the true value of the quantity being estimated. MSE is a risk function, corresponding to the expected value of the squared error loss or quadratic loss. MSE measures the average of the square of the "error." The error is the amount by which the estimator differs from the quantity to be estimated. The difference occurs because of randomness or because the estimator doesn't account for information that could produce a more accurate estimate.

The mean squared error (MSE) for our practical purposes allows us to compare the "true" pixel values of our original image to our degraded image. The MSE represents the average of the squares of the "errors" between our actual image and our noisy image. The error is the amount by which the values of the original image differ from the degraded image.

The proposal is that the higher the PSNR, the better degraded image has been reconstructed to match the original image and the better the reconstructive algorithm. This would occur because to minimize the MSE between images with respect the maximum signal value of the image The Mean Squared Error (MSE) is a measure of how close a fitted line is to data points. For every data point, you take the distance vertically from the point to the corresponding y value on the curve fit, this is known as the error, and square the value. Next you add up all those values for all data points, and divide by the number of points. The reason for squaring is so negative values do not cancel positive values. The smaller the Mean Squared Error, the closer the fit is to the data. The MSE has the units squared of whatever is plotted on the vertical axes.

The MSE of an estimator with respect to the estimated parameter $\theta$ is defined as

$$
\operatorname{MSE}(\hat{\theta})=E\left[(\hat{\theta}-\theta)^{2}\right]
$$

The MSE is equal to the sum of the variance and the squared bias of the estimator

The MSE thus assesses the quality of an estimator in terms of its variation and unbiasedness. Note that the MSE is not equivalent to the expected value of the absolute error. MSE is an expectation; it is a scalar, and not a random variable. It may be a function of the unknown parameter $\theta$, but it does not depend on any random quantities. However, when MSE is

$$
\operatorname{MSE}(\hat{\theta})=\operatorname{var}(\hat{\theta})+\left(\operatorname{Bias}(\hat{\theta}-\theta)^{2}\right)
$$

computed for a particular estimator of $\theta$ the true value of which is not known, it will be subject to estimation error. In a Bayesian sense, this means that there are cases in which it may be treated as a random variable.

Maxerr is the maximum absolute squared deviation of the

$$
s=\sum_{i=1}^{n} f\left(y_{i}\right)\left(x_{i}-x_{i-1}\right)
$$

\begin{tabular}{|c|c|c|c|c|c|c|c|c|}
\hline & \multicolumn{4}{|c|}{ Original Image } & \multicolumn{4}{|c|}{ Enhancement Image } \\
\hline $\begin{array}{l}\text { Image } \\
\text { Name }\end{array}$ & $\begin{array}{l}\text { PSN } \\
\mathrm{R}\end{array}$ & MSE & $\begin{array}{l}\text { Ma } \\
\text { xerr }\end{array}$ & L2rat & $\begin{array}{l}\text { PSN } \\
\mathrm{R}\end{array}$ & MSE & $\begin{array}{l}\text { Ma } \\
\text { xerr }\end{array}$ & $\begin{array}{l}\mathrm{L} 2 \mathrm{r} \\
\text { at }\end{array}$ \\
\hline $\begin{array}{l}\text { 01_1.b } \\
\mathrm{mp}\end{array}$ & $\begin{array}{l}17.22 \\
015\end{array}$ & $\begin{array}{l}1233 . \\
291\end{array}$ & 96 & $\begin{array}{l}0.942 \\
019\end{array}$ & $\begin{array}{l}17.2 \\
467\end{array}$ & $\begin{array}{l}1.2258 \\
\mathrm{e}+03\end{array}$ & 96 & $\begin{array}{l}0.9 \\
423\end{array}$ \\
\hline $\begin{array}{l}\text { 01_2.b } \\
\mathrm{mp}\end{array}$ & $\begin{array}{l}17.22 \\
241\end{array}$ & $\begin{array}{l}1232 . \\
648\end{array}$ & 96 & $\begin{array}{l}0.941 \\
883\end{array}$ & $\begin{array}{l}17.2 \\
977\end{array}$ & $\begin{array}{l}1.2115 \\
\mathrm{e}+03\end{array}$ & 96 & $\begin{array}{l}0.9 \\
430\end{array}$ \\
\hline $\begin{array}{l}01 \_3 . b \\
\mathrm{mp}\end{array}$ & $\begin{array}{l}17.26 \\
484\end{array}$ & $\begin{array}{l}1220 . \\
664\end{array}$ & 96 & $\begin{array}{l}0.942 \\
606\end{array}$ & $\begin{array}{l}17.2 \\
717\end{array}$ & $\begin{array}{l}1.2187 \\
\mathrm{e}+03\end{array}$ & 96 & $\begin{array}{l}0.9 \\
429\end{array}$ \\
\hline $\begin{array}{l}\text { 01_4.b } \\
\mathrm{mp}\end{array}$ & $\begin{array}{l}17.25 \\
322\end{array}$ & $\begin{array}{l}223 . \\
936\end{array}$ & 96 & $\begin{array}{l}0.942 \\
346\end{array}$ & $\begin{array}{l}17.2 \\
972\end{array}$ & $\begin{array}{l}1.2116 \\
\mathrm{e}+03\end{array}$ & 96 & $\begin{array}{l}0.9 \\
428\end{array}$ \\
\hline $\begin{array}{l}\text { 01_5.b } \\
\mathrm{mp}\end{array}$ & $\begin{array}{l}17.27 \\
137\end{array}$ & $\begin{array}{l}1218 . \\
831\end{array}$ & 96 & $\begin{array}{l}0.942 \\
757\end{array}$ & $\begin{array}{l}17.2 \\
775\end{array}$ & $\begin{array}{l}1.2171 \\
\mathrm{e}+03\end{array}$ & 96 & $\begin{array}{l}0.9 \\
424\end{array}$ \\
\hline $\begin{array}{l}01 \_6 . b \\
\mathrm{mp}\end{array}$ & $\begin{array}{l}17.23 \\
966\end{array}$ & $\begin{array}{l}1227 . \\
763\end{array}$ & 96 & $\begin{array}{l}0.942 \\
152\end{array}$ & $\begin{array}{l}17.2 \\
519\end{array}$ & $\begin{array}{l}1.2243 \\
\mathrm{e}+03\end{array}$ & 96 & $\begin{array}{l}0.9 \\
419\end{array}$ \\
\hline $\begin{array}{l}\text { 01_7.b } \\
\mathrm{mp}\end{array}$ & $\begin{array}{l}17.23 \\
285\end{array}$ & $\begin{array}{l}1229 . \\
688\end{array}$ & 96 & $\begin{array}{l}0.941 \\
959\end{array}$ & $\begin{array}{l}17.2 \\
778\end{array}$ & $\begin{array}{l}1.2170 \\
\mathrm{e}+03\end{array}$ & 96 & $\begin{array}{l}0.9 \\
425\end{array}$ \\
\hline $\begin{array}{l}\text { 01_8.b } \\
\mathrm{mp}\end{array}$ & $\begin{array}{l}17.27 \\
27\end{array}$ & $\begin{array}{l}1218 . \\
457\end{array}$ & 96 & $\begin{array}{l}0.942 \\
438\end{array}$ & $\begin{array}{l}17.2 \\
620\end{array}$ & $\begin{array}{l}1.2215 \\
\mathrm{e}+03\end{array}$ & 96 & $\begin{array}{l}0.9 \\
422\end{array}$ \\
\hline $\begin{array}{l}\text { 01_9.b } \\
\text { mp }\end{array}$ & $\begin{array}{l}17.25 \\
091\end{array}$ & $\begin{array}{l}1224 . \\
586\end{array}$ & 96 & $\begin{array}{l}0.942 \\
487\end{array}$ & $\begin{array}{l}17.2 \\
227\end{array}$ & $\begin{array}{l}1.2326 \\
\mathrm{e}+03\end{array}$ & 96 & $\begin{array}{l}0.9 \\
419\end{array}$ \\
\hline $\begin{array}{l}01 \_10 . \\
\text { bmp }\end{array}$ & $\begin{array}{l}17.19 \\
228\end{array}$ & $\begin{array}{l}1241 . \\
231\end{array}$ & 96 & $\begin{array}{l}0.941 \\
457\end{array}$ & $\begin{array}{l}17.2 \\
546\end{array}$ & $\begin{array}{l}1.2235 \\
\mathrm{e}+03\end{array}$ & 96 & $\begin{array}{l}0.9 \\
423\end{array}$ \\
\hline
\end{tabular}

data fingerprints images.

L2RAT is the ratio of the squared norm of the signal or image approximation to the input image

Table1: Statistical Quality Measures between Original and Enhanced Image (Images 1_1to 1_10)

Table2: Statistical Quality Measures between Original and Enhanced Image (Images 2_1to 2_10)

\begin{tabular}{|l|l|l|l|l|l|l|l|l|}
\hline & \multicolumn{4}{|l|}{ Original Image } & \multicolumn{4}{|l|}{ Enhancement Image } \\
\hline $\begin{array}{l}\text { Image } \\
\text { Name }\end{array}$ & $\begin{array}{l}\text { PSN } \\
\mathrm{R}\end{array}$ & MSE & $\begin{array}{l}\text { Ma } \\
\text { xerr }\end{array}$ & L2rat & $\begin{array}{l}\text { PSN } \\
\mathrm{R}\end{array}$ & MSE & $\begin{array}{l}\text { Ma } \\
\text { xerr }\end{array}$ & $\begin{array}{l}\text { L2r } \\
\text { at }\end{array}$ \\
\hline 02_1.b & 17.25 & 1224 & 96 & 0.942 & 17.3 & 1.2100 & 96 & 0.9 \\
\hline
\end{tabular}




\begin{tabular}{|c|c|c|c|c|c|c|c|c|}
\hline $\mathrm{mp}$ & 144 & 436 & & 338 & 028 & $\mathrm{e}+03$ & & 431 \\
\hline $\begin{array}{l}\text { 02_2.b } \\
\mathrm{mp}\end{array}$ & $\begin{array}{l}17.25 \\
68\end{array}$ & $\begin{array}{l}1222 . \\
928\end{array}$ & 96 & $\begin{array}{l}0.942 \\
372\end{array}$ & $\begin{array}{l}17.2 \\
945\end{array}$ & $\begin{array}{l}1.2124 \\
\mathrm{e}+03\end{array}$ & 96 & $\begin{array}{l}0.9 \\
426\end{array}$ \\
\hline $\begin{array}{l}\text { 02_3.b } \\
\mathrm{mp}\end{array}$ & $\begin{array}{l}17.30 \\
647\end{array}$ & $\begin{array}{l}1209 . \\
021\end{array}$ & 96 & $\begin{array}{l}0.942 \\
981\end{array}$ & $\begin{array}{l}17.2 \\
779\end{array}$ & $\begin{array}{l}1.2170 \\
\mathrm{e}+03\end{array}$ & 96 & $\begin{array}{l}0.9 \\
425\end{array}$ \\
\hline $\begin{array}{l}\text { 02_4.b } \\
\mathrm{mp}\end{array}$ & $\begin{array}{l}17.27 \\
913\end{array}$ & $\begin{array}{l}1216 . \\
654\end{array}$ & 96 & $\begin{array}{l}0.942 \\
681\end{array}$ & $\begin{array}{l}17.3 \\
150\end{array}$ & $\begin{array}{l}1.2067 \\
e+03\end{array}$ & 96 & $\begin{array}{l}0.9 \\
431\end{array}$ \\
\hline $\begin{array}{l}\text { 02_5.b } \\
\mathrm{mp}\end{array}$ & $\begin{array}{l}17.25 \\
851\end{array}$ & $\begin{array}{l}1222 . \\
446\end{array}$ & 96 & $\begin{array}{l}0.942 \\
475\end{array}$ & $\begin{array}{l}17.1 \\
967\end{array}$ & $\begin{array}{l}1.2400 \\
\mathrm{e}+03\end{array}$ & 96 & $\begin{array}{l}0.9 \\
415\end{array}$ \\
\hline $\begin{array}{l}\text { 02_6.b } \\
\mathrm{mp}\end{array}$ & $\begin{array}{l}17.29 \\
41\end{array}$ & $\begin{array}{l}1212 . \\
468\end{array}$ & 96 & $\begin{array}{l}0.942 \\
658\end{array}$ & $\begin{array}{l}17.2 \\
565\end{array}$ & $\begin{array}{l}1.2230 \\
\mathrm{e}+03\end{array}$ & 96 & $\begin{array}{l}0.9 \\
424\end{array}$ \\
\hline $\begin{array}{l}\text { 02_7.b } \\
\mathrm{mp}\end{array}$ & $\begin{array}{l}17.26 \\
077\end{array}$ & $\begin{array}{l}1221 . \\
81\end{array}$ & 96 & $\begin{array}{l}0.942 \\
435\end{array}$ & $\begin{array}{l}17.3 \\
165\end{array}$ & $\begin{array}{l}1.2062 \\
\mathrm{e}+03\end{array}$ & 96 & $\begin{array}{l}0.9 \\
432\end{array}$ \\
\hline $\begin{array}{l}\text { 02_8.b } \\
\mathrm{mp}\end{array}$ & $\begin{array}{l}17.28 \\
232\end{array}$ & $\begin{array}{l}1215 . \\
762\end{array}$ & 96 & $\begin{array}{l}0.942 \\
641\end{array}$ & $\begin{array}{l}17.2 \\
518\end{array}$ & $\begin{array}{l}1.2243 \\
\mathrm{e}+03\end{array}$ & 96 & $\begin{array}{l}0.9 \\
419\end{array}$ \\
\hline $\begin{array}{l}\text { 02_9.b } \\
\mathrm{mp}\end{array}$ & $\begin{array}{l}17.26 \\
477\end{array}$ & $\begin{array}{l}1220 . \\
686\end{array}$ & 96 & $\begin{array}{l}0.942 \\
576\end{array}$ & $\begin{array}{l}17.2 \\
826\end{array}$ & $\begin{array}{l}1.2157 \\
\mathrm{e}+03\end{array}$ & 96 & $\begin{array}{l}0.9 \\
430\end{array}$ \\
\hline $\begin{array}{l}\text { 02_10. } \\
\text { bmp }\end{array}$ & $\begin{array}{l}17.29 \\
014\end{array}$ & $\begin{array}{l}1213 . \\
575\end{array}$ & 96 & $\begin{array}{l}0.942 \\
636\end{array}$ & $\begin{array}{l}17.2 \\
456\end{array}$ & $\begin{array}{l}1.2261 \\
e+03\end{array}$ & 96 & $\begin{array}{l}0.9 \\
423\end{array}$ \\
\hline $\begin{array}{l}\text { Image } \\
\text { Name }\end{array}$ & $\begin{array}{l}\text { PSN } \\
\text { R }\end{array}$ & MSE & $\begin{array}{l}\mathrm{Ma} \\
\text { xerr }\end{array}$ & L2rat & $\begin{array}{l}\text { PSN } \\
\mathrm{R}\end{array}$ & MSE & $\begin{array}{l}\text { Ma } \\
\text { xerr }\end{array}$ & $\begin{array}{l}\text { L2r } \\
\text { at }\end{array}$ \\
\hline
\end{tabular}

\section{Graph1: Statistical Quality Measures between Original} and Enhanced Image (Images 1_1to 1_10)

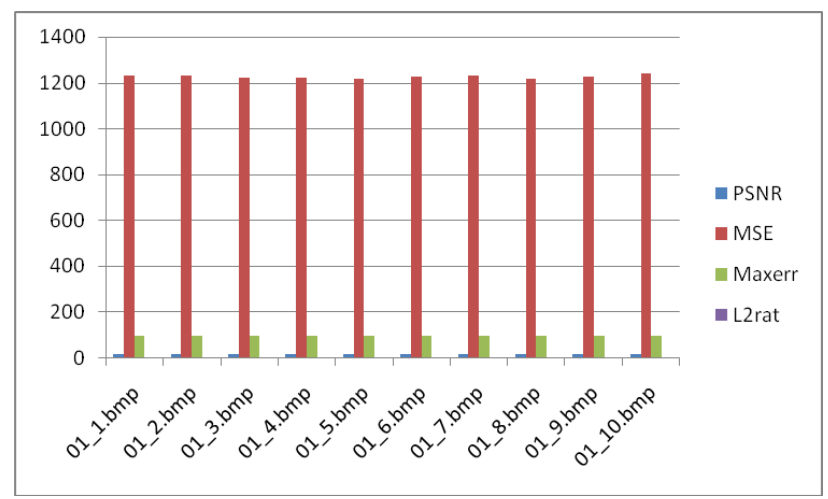

Graph2: Statistical Quality Measures between Original and Enhanced Image (Images 2_1to 2_10)

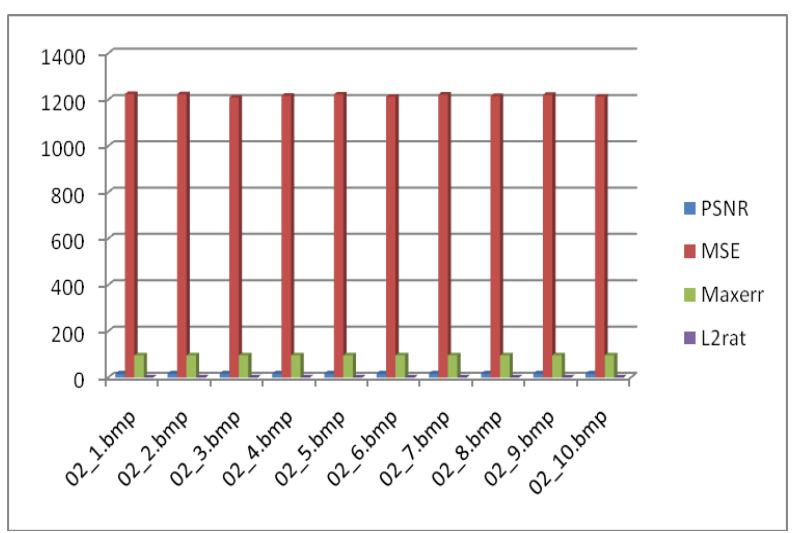

\section{CONCLUSION}

In large scale deployment of fingerprint recognition systems, especially in rural fingerprints database, there are some challenges involved. Along with the sensor noise and poor image quality, presence of scars and warts, and deteriorating ridge/minutiae patterns in fingerprints from rural population affect the data distribution. Since there is no research that evaluates the performance of automatic fingerprint verification/identification in rural fingerprints databases.

Studied the performance using standard fingerprint recognition systems and fingerprint databases collected from the rural fingerprints databases, Indian population now a day's it has been work on unique identification where but when there is enhancement with such noisy fingerprints hence this research work concentrated on same. In this paper perform histogram equalization for enhancement poor quality fingerprint images of rural fingerprint image database. Selected 100 images out of 1632 . In this paper sample result of first twenty images out of hundred given .it is found that histogram equalization is very much useful to enhance the quality of rural fingerprint image database.

\section{ACKNOWLEDGMENTS}

We are very much thankful to. Image Analysis and Biometrics (IAB) $\mathrm{Lab}$ at Indraprastha Institute of Information Technology, IIIT Delhi for providing rural fingerprint database.

\section{REFERENCES}

[1] M. Vatsa, R. Singh, S. Bharadwaj, H. Bhatt, R Mashruwala "Analyzing Fingerprints of Indian Population Using Image Quality": A UIDAI Case Study 1 - IIIT Delhi, India 2 UIDAI, India.

[2] C. Puri, K. Narang, A. Tiwari, M. Vatsa, and R. Singh, "On Analysis of Rural and Urban Indian Fingerprint Images" IIIT Delhi, India.

[3] D. Maltoni, D. Maio, A. Jain, and S. Prabhakar, "Handbook of fingerprint recognition" Springer Verlag, 2003.

[4] Jain, A.K., Prabhakar, S., Hong, L., Pankanti, S."Filter bank-based fingerprint Matching", IEEE Transactions on Image Processing, 9(5) (2000) 846-859.

[5] Tao, XunqiangInst. of Autom., Beijing, China Yang, Xin; Zang, Yali; Jia, Xiaofei; Tian, JianPage(s): 170 175."A novel measure of fingerprint image quality using Principal Component Analysis (PCA)" Biometrics (ICB), 2012 5th IAPR International Conference on: March 29 2012-April 12012.

[6] M.M.Kazi, A.V.Mane, R.R.Maza, K.V.Kale,"Comparison of fingerprint enhancement techniques through mean square error and Peak-signal to noise ratio "International Journal on computer science and engineering (IJCSE).ISSN:0975-3397 Vol.3 No.1 Jan 2011".।

[7] NFIQ. http://fingerprint.nist.gov/nbis/index.html, last accessed on Jan 25, 2010.

[8] U. I. A. of India. http://www.uidai.gov.in/, last accessed on Jan 25, 2010.

[9] Huynh-Thu, Scope of validity of PSNR in image/video quality assessment, Electronics Letters, 44, 2008, pp. 800-801. 